\title{
ESTUDO DE CASO: ANÁLISE DO POSTO DE TRABALHO E DESCONFORTO MUSCULOESQUELÉTICOS EM ESCRITURÁRIA
}

\section{CASE STUDY: ANALYSIS OF THE WORKSTATION AND DISCOMFORT SKELETAL MUSCLE IN CLERK}

\author{
João Paulo Domingues Pizzo (Autor 1) \\ Kathlen Cristine Milani (Autor 2) \\ Flávio Ventura (Autor 3) \\ Rosangela Monteiro dos Santos (Autor 4) \\ (1) Faculdade de Tecnologia de Jahu (FATEC-JAHU) \\ e-mail: jppizzol1@gmail.com \\ (2) Faculdade de Tecnologia de Jahu (FATEC-JAHU) \\ e-mail: kathlenmilani@hotmail.com

\begin{abstract}
(3) Universidade Estadual Paulista / Faculdade de Tecnologia de Jahu e-mail: flavio_ventura.ig.com.br

(4) Universidade Estadual Paulista / Faculdade de Tecnologia de Jahu rosangela.santos4@fatec.sp.gov.br
\end{abstract}

Palavras-chave: Ergonomia em escritório, Postura Sentada, desconforto musculoesquelético.

RESUMO: As doenças ocupacionais são adquiridas por meio de exposição dos trabalhadores aos agentes ambientais, físicos, químicos, biológicos e ergonômicos em situação acima do limite tolerável. Dos agentes citados, o ergonômico é o mais recente, sendo responsável por ocasionar doenças do trabalho como Lesões por Esforço Repetitivo (LER) e Distúrbios Osteomusculares Relacionados ao Trabalho (DORT). A Ergonomia é uma área multidisciplinar que abrange as áreas exatas, humanas e da saúde que busca estudar as relações entre o homem e o posto de trabalho analisando as condições gerais, móveis, equipamentos, posturas e problemas. Os objetivos de artigo foram: avaliar o posto de trabalho de uma funcionária do setor financeiro de uma loja de móveis, analisar o Layout, as posturas corporais durante as atividades profissionais do escriturário, identificar o índice de desconforto musculoesquelético e demais problemas físicos causados pelo trabalho sentado. Para a coleta de dados foram realizadas análise de observação, entrevista e aplicação do questionário nórdico.

Key words: Ergonomics in office, posture siting, discomfort sketeletal muscle

ABSTRACT: Occupational diseases are feeling by exposing workers to environmental, physical, chemical, biological and ergonomic agents in situations the tolerable limit over. Despite of the mentioned agents, the ergonomic one is the most recent, being responsible for causing occupational diseases like Repetitive Strain Injuries (RSI) and Work-Related Musculoskeletal Disorders (DORS). Ergonomics is a multidisciplinary area that covers the exact areas, human and health, which seeks to study the relationships between man and the workplace by analyzing general conditions, furniture, equipment, postures and problems. Here are the objectives of the present article were: to evaluate the work position of a female employee in the financial sector of a furniture store, to analyze the Layout, the body postures during the professional activities of the clerk, identify the index of musculoskeletal discomfort and other physical problems caused by Work. For the data collection, observation, interview and application of the Nordic questionnaire were been performed. 


\section{$16^{\circ}$ \\ ERGODESIGN USIHC CINAHPA}

$16^{\circ}$ Ergodesign - Congresso Internacional de Ergonomia e Usabilidade de Interfaces Humano Tecnológica: Produto, Informações Ambientes Construídos e Transporte

$16^{\circ}$ USIHC - Congresso Internacional de Ergonomia e Usabilidade de Interfaces Humano Computador

CINAHPA | 2017 - Congresso Internacional de Ambientes Hipermídia para Aprendizagem.

\section{Introdução}

As mudanças que se processam no mundo do trabalho remetem a um novo modelo de relações econômicas, políticas, sociais e culturais. Neste sentido, as evoluções tecnológicas são as principais que exigem reestruturações no perfil organizacional das empresas. Quase sempre, essas alterações no ambiente de trabalho resultam em ampliação das jornadas e aumento do ritmo, além de novas formas administrativas e operacionais (GOMES, 2010).

Neste sentido, surge a necessidade de se buscar novos conhecimentos sobre o ambiente em que ocorre o trabalho, bem como suas repercussões para a empresa como um todo e para a vida do trabalhador, seja no sentido físico, emocional, social, psíquico ou cultural.

Diante do exposto é relevante investigar as condições de trabalho de pessoas que trabalham na postura sentada por tempo prolongado.

\subsection{Objetivos}

Este trabalho tem como objetivo principal fazer uma avaliação ergonômica do posto de trabalho do setor financeiro de uma indústria e propor algumas sugestões e recomendações, baseadas nos resultados dessa avaliação e no conteúdo teórico pesquisado na literatura sobre ergonomia.

\section{Referencial teórico}

Nos projetos do trabalho e nas situações cotidianas, a ergonomia dá ênfase ao homem. As condições de insegurança, insalubridade, desconforto e ineficiência são eliminadas adaptando-as às capacidades, limitações físicas e psicológicas.

Grandjean (1998) afirma que o sistema homemmáquina é uma relação de reciprocidade entre a máquina e o ser humano que a opera. Ao homem é estabelecida a tarefa de decidir, pois recebe visualmente a informação (no caso, dos monitores de computador) e precisa entender e interpretar a fim de tomar decisões e agir de forma correta.
Como causas de desconforto em postos de trabalho com computadores se destacam: altura do teclado muito baixa em relação ao piso, altura do teclado muito alta em relação à mesa, falta de apoios adequados para os antebraços e punhos, cabeça muito inclinada para frente, pouco espaço lateral para as pernas e posicionamento inadequado do teclado.

\subsection{Postura sentada}

A postura sentada gera várias alterações nas estruturas musculoesqueléticas da coluna lombar, inclusive aumenta em aproximadamente $35 \%$ a pressão interna no núcleo do disco intervertebral. Todas as estruturas (ligamentos, pequenas articulações e nervos) são alongadas, reduzindo a circulação em retorno dos membros inferiores e promovendo desconfortos na região do pescoço e membros superiores. Caso o indivíduo sentado permaneça na postura incorreta por longo período as alterações são potencializadas, sendo que a pressão intradiscal aumenta para mais de $70 \%$. Este fato pode predispor ao indivíduo os maiores índices de desconfortos gerais, tais como: dor, sensação de peso e formigamento em diferentes partes do corpo e, principalmente a processos degenerativos, como a hérnia de disco (COURY, 1994).

\subsection{Questionário Nórdico Musculoesquelético (NMQ)}

Para facilitar o estudo e avaliar com maior precisão os dados coletados, foi aplicado na funcionária o NMQ. Após seu preenchimento, foi possível verificar a ocorrência de sintomas muscoesqueléticos que até então eram despercebidos.

Esta ferramenta foi traduzida para diversos idiomas, dando origem a muitos estudos empíricos. Sua versão brasileira foi proposta por Barros e Alexandre (2003) com o nome de Questionário Nórdico de Sintomas Osteomusculares (QNSO). A partir de então, diversas análises foram realizadas, as quais alcançaram resultados satisfatórios. Com ele é possível detectar distúrbios osteomusculares e sintomas de DORT. 


\section{$16^{\circ}$ \\ ERGODESIGN USIHC CINAHPA}

Dada a simplicidade e os bons índices de confiabilidade, sua utilização é indicada em investigações epidemiológicas e estudos que busquem mensurar a incidência dos sintomas osteomusculares.

\section{Métodos de pesquisa}

Foi realizado um estudo de caso com uma funcionária do setor financeiro de uma indústria moveleira localizada em uma cidade no interior de São Paulo com a finalidade de analisar o layout do ambiente de trabalho, os posicionamentos corporais e o índice de desconforto musculoesquelético.

Ao final, foi aplicado o NMQ para saber quais são as regiões corporais com maiores desconfortos nos últimos seis meses.

A figura 2 mostra o ambiente de trabalho da funcionária.

Figura 2: Ambiente de trabalho.

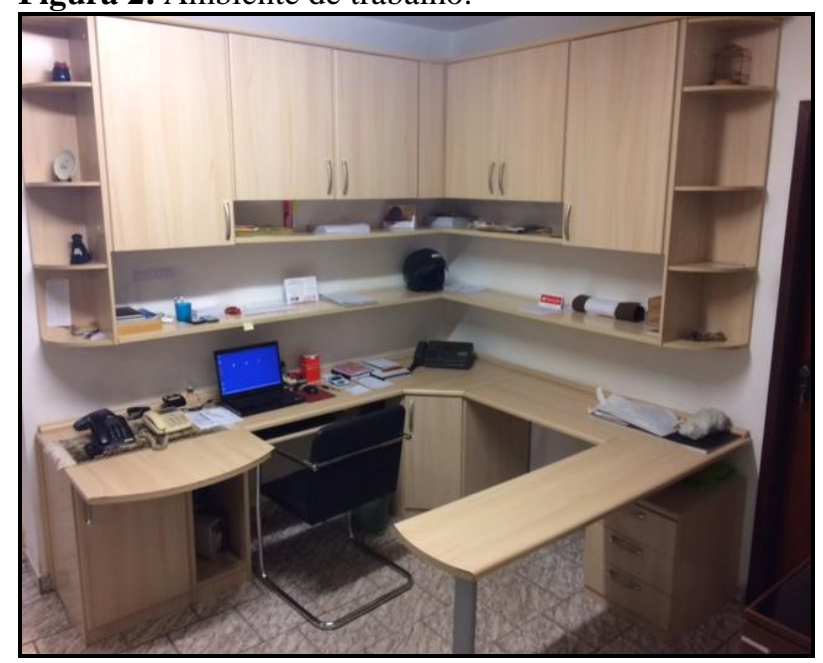

Fonte: O autor, 2017.

\subsection{Local}

A indústria de móveis analisada é uma empresa de médio porte fundada em 1985 que auxiliada pela tecnologia, pesquisa e treinamento, procura atender plenamente aos seus clientes, dando opções, sugestões e alternativas para que o móvel ou ambiente procurado fique o mais funcional e aconchegante possível, livre de excessos e do gosto $16^{\circ}$ Ergodesign - Congresso Internacional de Ergonomia e Usabilidade de Interfaces Humano Tecnológica: Produto, Informações Ambientes Construídos e Transporte

$16^{\circ}$ USIHC - Congresso Internacional de Ergonomia e Usabilidade de Interfaces Humano Computador

CINAHPA | 2017 - Congresso Internacional de Ambientes Hipermídia para Aprendizagem.

de quem realmente vai usufruí-lo.

\subsection{Participante}

Para o estudo, foi escolhida uma funcionária do setor financeiro. Ela trabalha oito horas no local, há três anos, diariamente das 08:00 as 17:30, com intervalo de 1:30 para almoço, e aos sábados até as 13:00.

\subsection{Procedimento de análise dos dados}

Foi analisado o ambiente como um todo, mas principalmente a altura, cor e modelo da mesa e cadeira. Analisou-se o teclado, mouse e monitor. Observou-se também o espaço disponível, iluminação, nível de ruído e ventilação.

Foram verificadas quantas horas a trabalhadora passa no local na mesma posição e há quanto tempo está desenvolvendo o trabalho na empresa. Foi aplicado um questionário a fim de descobrir se sente dores e se eventualmente são causadas devido ao ambiente de trabalho, onde ficou constatado que há indícios de LER/DORT.

Também foi averiguado se o seu serviço está sendo desenvolvido da maneira adequada, para que ao final possam ser implantadas as melhorias cabíveis, evitando assim dores e possíveis desconfortos, doenças ou problemas futuros.

\section{Resultados e discussões}

\subsection{Layout}

O layout foi visto como um todo bem como a estrutura do escritório e ambiente de trabalho em questão. Com auxílio de uma trena a sala foi medida, além de ser analisado criteriosamente o local e a disposição de cada equipamento.

\subsubsection{Mobiliário e equipamentos}

Do mobiliário e equipamentos presentes no local, foram observados os tamanhos, as cores, a qualidade e apresentaram as seguintes características: 


\section{$16^{\circ}$ \\ ERGODESIGN USIHC CINAHPA}

- Cor: bege $\quad$ Medida da mesa: $0,73 \mathrm{~m}$, 0,70m, 1,15m (A x L x C);

- Medida do armário principal: 1,22m, 0,55m, 2,38m (A x L x C);

- Medida do armário secundário: 1,22m, $0,55 \mathrm{~m}, 1,68 \mathrm{~m}(\mathrm{~A} \times \mathrm{L} \times \mathrm{C})$;

Nas extremidades de ambos os armários há cantoneiras dando um melhor acabamento e dentro deles são guardados documentos da empresa como: livros contábeis, notas fiscais e fiscais de recolhimento entre outros.

Além da mesa, ao seu redor existem bancadas para melhor acomodar os utensílios de trabalho da funcionária.

A Figura 4 ilustra com maior clareza os movimentos por ela realizados.

Figura 4: Postura da funcionária ao trabalho

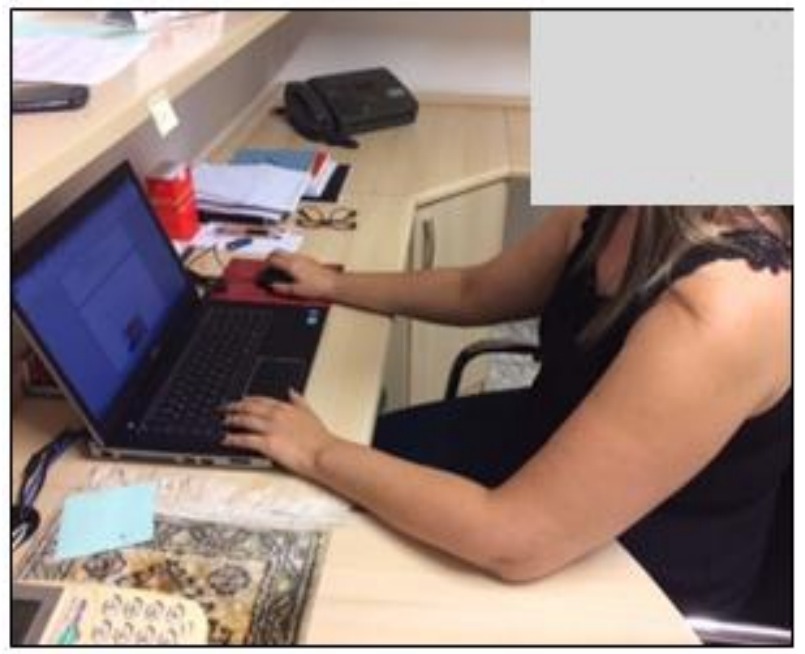

Fonte: O Autor, 2017.

\subsubsection{Aferição de medidas}

Foi feita uma antropometria na funcionária e foram também medidos os móveis. Após serem coletadas todas as medidas, foi constatado que existem algumas discrepâncias com o disposto na Norma Regulamentadora 17 (NR-17) que estabelece parâmetros que permitam a adaptação das condições de trabalho às características psicofisiológicas dos trabalhadores, de modo a proporcionar um máximo de conforto, segurança e $16^{\circ}$ Ergodesign - Congresso Internacional de Ergonomia e Usabilidade de Interfaces Humano Tecnológica: Produto, Informações Ambientes Construídos e Transporte

$16^{\circ}$ USIHC - Congresso Internacional de Ergonomia e Usabilidade de Interfaces Humano Computador

CINAHPA | 2017 - Congresso Internacional de Ambientes Hipermídia para Aprendizagem.

desempenho eficiente.

As desconformidades foram:

- A funcionária não dispõe de uma cadeira que atenda as recomendações consideradas ergonomicamente ideais para esta atividade;

- Não há regulagem de altura do monitor e nem apoio, onde a altura mínima é de 26 centímetros a partir de seu plano vertical, fazendo com que a funcionária fique com pescoço flexionado durante a sua jornada.

- A bancada sem material de consulta que deveria ter, no mínimo, profundidade de 75 (setenta e cinco) centímetros medidos a partir de sua borda frontal e largura de 90 (noventa) centímetros, apresenta profundidade de 70 (setenta) centímetros e largura de 75 (setenta e cinco) centímetros);

- A bancada com material de consulta que deveria ter, no mínimo, profundidade de 90 (noventa) centímetros a partir de sua borda frontal e largura de 100 (cem) centímetros, apresenta profundidade de 83 (oitenta e três centímetros) e largura de 96 (noventa e seis) centímetros;

- A superfície de trabalho que deveria ter regulagem de altura em um intervalo mínimo de 13 (treze) centímetros, medidos de sua face superior, permitindo o apoio das plantas dos pés no piso, não apresenta esta característica;

- O espaço sob a superfície de trabalho que deve ter profundidade livre mínima de 45 (quarenta e cinco) centímetros ao nível dos joelhos tem apenas 13 (treze) centímetros.

Entretanto, algumas medidas e características elencadas no disposto da NR-17 foram atendidas, tais como: arredondadas;

- O plano de trabalho possui bordas

- $\mathrm{O}$ dispositivo de apontamento na tela (mouse) está apoiado na mesma superfície do teclado e colocado em área de fácil alcance com espaço suficiente para sua livre utilização;

- O espaço sob a superfície de trabalho que deve ter no mínimo 70 (setenta) centímetros ao nível dos pés, medidos de sua borda frontal tem 75 (setenta e cinco) centímetros; 


\section{$16^{\circ}$ \\ ERGODESIGN USIHC CINAHPA}

- Embora a cadeira utilizada não atenda a todos os conceitos ergonômico, a planta dos pés alcançam o piso, permitindo que seus pés fiquem apoiados.

As demais medidas, características e exigências da NR-17, só estarão padronizadas após aquisição de uma cadeira adequada para esta atividade.

\section{do $N M Q$ \\ 4.1.4 Resultados obtidos pela aplicação}

As principais áreas com presença de sintomas, desconforto, incômodo ou dor durante os últimos seis meses e a região do corpo correspondente, podem ser visualizadas na Gráfico 1. Os números da parte inferior do gráfico ( 1 a 6$)$ correspondem a frequência dos últimos seis meses pesquisados.

Nota-se, que a funcionária apresenta desconforto em todas as regiões dos membros nesse período, mas as de maior incidência são ombros, punhos e mãos (praticamente nos últimos seis meses) e parte inferior das costas (pouco mais de cinco meses).

Gráfico 1: Frequência de desconforto por zona corporal nos últimos seis meses.

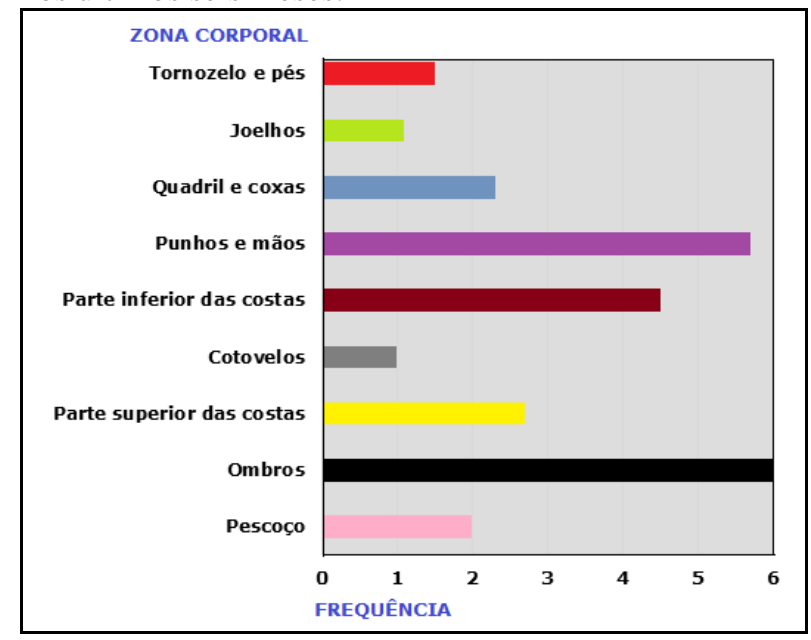

Fonte: Elaborado pelos autores, 2017.

O questionário também foi aplicado referindo-se aos desconfortos e dores decorrentes nos últimos sete dias, que podem ser melhor analisados no Gráfico 2. $16^{\circ}$ Ergodesign - Congresso Internacional de Ergonomia e Usabilidade de Interfaces Humano Tecnológica: Produto, Informações Ambientes Construídos e Transporte

$16^{\circ}$ USIHC - Congresso Internacional de Ergonomia e Usabilidade de Interfaces Humano Computador

CINAHPA | 2017 - Congresso Internacional de Ambientes Hipermídia para Aprendizagem.

A metodologia e o modelo de gráfico utilizados para a obtenção destas informações foram as mesmas do Gráfico 1. A diferença é que dessa vez os números inferiores ( 1 a 7 ) se referem aos últimos sete dias. Ao analisar o referido gráfico, nota-se que as dores no pescoço que anteriormente não a incomodavam tanto, têm aparecido com maior frequência nos últimos cinco dias e as dores nos ombros, parte inferior das costas e punhos e mãos que eram as que mais a incomodavam, pouco sofreram alterações. Dores no quadril e coxas diminuíram, cotovelos também praticamente não se alterou e as dores e desconfortos nos tornozelos e pés e joelhos não a têm incomodado mais, ao menos nos últimos sete dias.

Gráfico 2- Frequência de desconforto por zona corporal nos últimos sete dias.

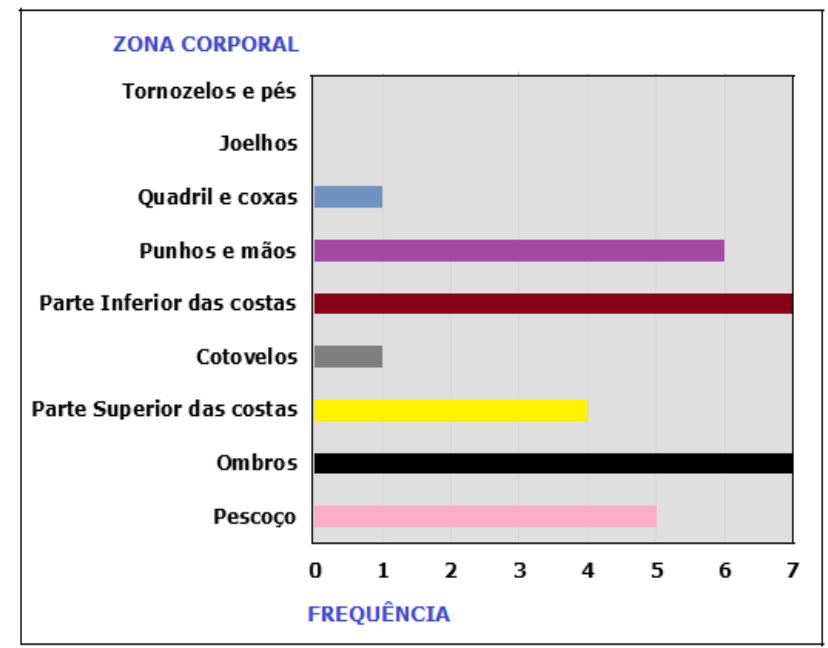

Fonte: Elaborado pelos autores, 2017.

\section{Conclusão}

Essa pesquisa teve a finalidade de analisar as condições de trabalho de uma escriturária, a postural corporal e o índice de desconforto musculoesquelético. Conclui-se portanto, que o ambiente de trabalho necessita de algumas modificações. A primeira medida a ser tomada é a aquisição de uma cadeira que ofereça maior conforto para a funcionária e que atenda as exigências da NR-17.

Além da cadeira, o monitor também não há regulagem de altura, fazendo que a funcionária fique com o pescoço flexionado o tempo todo para 


\section{$16^{\circ}$}

ERGODESIGN USIHC CINAHPA $16^{\circ}$ Ergodesign - Congresso Internacional de Ergonomia e Usabilidade de Interfaces Humano Tecnológica: Produto, Informações Ambientes Construídos e Transporte

$16^{\circ}$ USIHC - Congresso Internacional de Ergonomia e Usabilidade de Interfaces Humano Computador

CINAHPA | 2017 - Congresso Internacional de Ambientes Hipermídia para Aprendizagem.

baixo, a largura e a profundidade tanto da bancada com material de consulta quanto sem, não obedecem as medidas mínimas exigidas pela NR17 , a superfície de trabalho não tem regulagem de altura e o espaço entre a superfície de trabalho até os joelhos também não está com o mínimo exigido.

Os armários estão corretamente dispostos, ou seja, não paralelos com a borda da bancada de trabalho e numa altura ideal. A funcionária os organiza de acordo com as suas necessidades. Os documentos mais utilizados são dispostos nas prateleiras mais baixas onde seus braços alcançam. Documentos menos usados onde há necessidade de auxílio de uma escada, são dispostos nas prateleiras mais altas, evitando assim desconfortos e acidentes.

Para que todo esse arranjo alcance o nível desejado, bastam apenas alguns ajustes ergonômicos e uma instrução mais detalhada não só para a funcionária em questão, mas para toda a equipe de colaborares.

\section{Bibliografia}

BARROS, E. N.C.; ALEXANDRE, N.M.C. Crosscultural adaptation of the Nordic musculoskeletal questionnaire. International Nursing Review (INR). 2003; 50 (2): 101-08.

\section{COURY, HJC. Programa auto instrucional} para o controle de desconfortos posturais em indivíduos que trabalham sentados

(Dissertação de doutorado). Campinas:

Faculdade de Educação / Universidade Estadual de Campinas; 1994.

GOMES, Vantuir. Ergonomia: Postura Correta de Trabalho. Revista Brasileira de Engenharia, Minas Gerais, p. 17-29, dez. 2010.

GRANJEAN, E. Manual de Ergonomia: Adaptando o Trabalho ao Homem. 4 ed. Porto Alegre: Bookman, 1998. 